Canadian

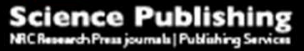

Canadian Journal of Civil Engineering Revue canadienne de génie civil

\title{
Project Delivery and Contracting Strategies for District Energy Projects in Canada
}

\begin{tabular}{|r|l|}
\hline Journal: & Canadian Journal of Civil Engineering \\
\hline Manuscript ID & cjce-2014-0259.R4 \\
\hline Manuscript Type: & Article \\
\hline Date Submitted by the Author: & 02-Jan-2016 \\
\hline Complete List of Authors: & $\begin{array}{l}\text { Mogerman, Aaron; University of British Columbia, } \\
\text { Mendis, Daylath; University of British Columbia, } \\
\text { Hewage, Kasun; University of British Columbia }\end{array}$ \\
\hline Keyword: & District energy projects, project delivery methods, contract strategies \\
\hline & \\
\hline
\end{tabular}

SCHOLARONE ${ }^{\text {IM }}$

Manuscripts 


\title{
Project Delivery and Contracting Strategies for District Energy Projects in Canada
}

\author{
Aaron Mogerman ${ }^{1}$, Daylath Mendis ${ }^{2}$, and Kasun N. Hewage ${ }^{3}$
}

\begin{abstract}
${ }^{1}$ Project Manager, UBC Infrastructure Development, University of British Columbia, BC, Canada, Phone: 1.604.822.0195, Email: Aaron.Mogerman@ubc.ca

${ }^{2} \mathrm{PhD}$ student, School of Engineering, University of British Columbia, BC, Canada, Phone:

1.250.869.9470, Email: daylathpm@yahoo.ca

${ }^{3}$ Associate Professor, School of Engineering, University of British Columbia, BC, Canada, Phone: 1.250.807.8176, Email: Kasun.Hewage@ubc.ca
\end{abstract}

\section{Corresponding Author}

Kasun Hewage, PhD, PEng

Associate Professor

The University of British Columbia

School of Engineering (Okanagan Campus)

Office: EME 4287 Lab: EME 3287

1137 Alumini Avenue, Kelowna, BC, Canada, V1V 1V7

Tel: 1.250 .807 .8176

Fax: 1.250.807.9850

Email: Kasun.Hewage@ubc.ca 


\begin{abstract}
New district energy projects facilitate to decentralize their energy supply, create efficiency in the production and distribution of energy, and enable the use of renewable fuels. Selection of an appropriate project delivery and contracting strategy is essential to achieve owner's key objectives over the lifecycle of a district energy facility.
\end{abstract}

The goal of this paper is to identify objectives of the owners in Canadian district energy projects, and then align those with project delivery and contracting strategy (PDCS) alternatives. The paper also provides a practical tool to assist owners in the selection of an appropriate PDCS for their district energy projects. This research has identified and validated key PDCS selection factors for Canadian district energy projects using Delphi based research method. The paper contributes to the body of knowledge by identifying PDCS alternatives, specifically for Canadian district energy projects, and selecting PDCS alternatives in the context of the project lifecycle.

KEY WORDS: District energy projects, project delivery methods, contract strategies 


\section{INTRODUCTION}

New energy systems are emerging as a viable way to supplement the traditional energy infrastructure in urban communities across North America. British Columbia has district energy projects located throughout the province, and a significant number of B.C. companies operating within the district energy sector (Ministry of Energy, Mines and Petroleum Resources, 2010). District energy systems rely on a central plant to produce heating and cooling capabilities and domestic hot water, all of which are distributed through a network of piping to groups of buildings. Unlike conventional, large utility providers within the traditional infrastructure, the owners and stakeholders of district energy systems are diverse, ranging from municipalities to institutions and private developers, all of whom see the benefit of a system that can provide locally distributed energy and alternative energy sources.

Planning and construction of a district energy system presents many of the same issues and difficulties as with a large energy infrastructure project, but these projects are unique in many ways. One way to ensure that such a project is successful, and that the project lifecycle objectives are met, is through the selection of a suitable project delivery strategy. A delivery strategy will drive project cost, schedule, and quality, and ultimately operating and maintenance costs. Owners should pursue a project delivery strategy that is most closely aligned with their specific key lifecycle objectives and long-term goals.

The aim of the research conducted to support this paper was to: (1) understand the most important objectives for owners in district energy projects in Canada, (2) align those objectives with project delivery and contracting strategy (PDCS) alternatives, and (3) provide a practical tool to assist owners with the selection of an appropriate PDCS for their district energy projects. The research specifically focused on understanding the relationship between 
a standard set of PDCS alternatives (i.e. the options for procurement, financing and management in the context of the roles and responsibilities of each contracted party) and the key PDCS selection factors (i.e. the objectives that will influence the owner's selection of the PDCS alternative. Understanding this relationship would help future owners of Canadian district energy projects to address the question: "Which PDCS alternative (or alternatives) should be used for the successful achievement of project's key lifecycle objectives?" The gaps in current research relating to PDCS decision-making are identified and provide direction for this research project. The two primary gaps in prior research on this subject are further defined. This research contributes to the body of knowledge in these two important areas. These areas represent gaps in prior research on this subject and are summarized as follows:

- Selection of PDCS alternatives specifically for district energy projects.

- Developing a tool to select PDCS alternatives in the context of the entire project lifecycle.

\section{BACKGROUND}

\section{District Energy Systems}

District heating traces its roots as far back as the popular hot water-heated baths and greenhouses of ancient Rome. District systems gained prominence in Europe during the Middle Ages and Renaissance, with one system in France in continuous operation since the 14th century (International District Energy Association, 2009). District energy systems are categorized based on different aspects. One grouping is derived from the heat transport fluid: low-pressure steam, hot water and hot air. Another classification is based on the thermal 
energy transported: heating, cooling, and cooling and heating. A further categorization of district heating system can be based on the type of heat resources: using a separate source of energy for heat or using recycled energy/heat (Rezaie and Rosen, 2011). District energy systems have higher efficiency than decentralized systems and offer better pollution control (Akhtari et al., 2003). The interest in District Energy from the electric utility sector is growing rapidly (Windsor Utilities Commission, 2014). According to the US Department of Energy’s Federal Energy Management Program, district energy systems are small, modular, decentralized, grid-connected or off-grid energy systems, located in or near the place where the energy is used (US DOE, 2011). District energy connects multiple energy users, through an underground piping network, and provides a medium that allows for the transfer of energy (IDEA, 2011). The energy can be transported via steam, hot water, or chilled water. A district energy system may be designed with a central energy plant, or with multiple plants, connected by pipes that provide space heating, hot water, steam, and chilled water to a group of buildings (Gilmour and Warren, 2008).

\section{Project Delivery Alternatives for Capital Building Projects}

The project delivery decision is clearly the owner's decision problem (Oyentuji, 2001) and the extent to which the owner's objectives are achieved depends greatly on the extent to which the owner's objectives can be aligned with those of the other stakeholders (Bowers et al., 2003).

An appropriate PDCS is an important tool in the promotion of the necessary harmony between the objectives of the owner and those of the other key stakeholders. The PDCS serves as the procurement approach, the financing strategy, and the management system for 
accomplishing the project's objectives, which together will deliver a project that is successful throughout its lifecycle ( Pishdad and Beliveau (2010). It has been estimated that the selection of a more efficient contracting method could reduce project cost by as much as $5 \%$ (Gordon, 1994).

Bowers et al. (2003) also looked to expand and validate the traditional list of viable PDCS options. The authors identified four main characteristics of PDCS alternatives: i.e. (1) sequence of project phases, (2) functional responsibility of each party, (3) contractual relationship of the parties, and (4) compensation approach for each contractual relationship.

Using these characteristics as a framework, and through an extensive industrial survey, the researchers validated twelve PDCS alternatives. Bowers et al. (2003) identified several key assumptions that influence the list of PDCS factors validated by their work. The PDCS options in their study exclude the pre-construction planning phase of the project lifecycle. In addition, the study did not fully consider commissioning and start up project phases and operate-maintain type of contracts. Lastly, the PDCS options considered are all based on $100 \%$ owner financing of the project. These omissions in the existing research represent a gap that is critical to the delivery of district energy projects. The research presented in this paper aims to address this gap.

Miller et al. (2003) concluded that project planning for public infrastructure is an owner-driven process that must correlate with the owner's overall economic needs and social policies. However, the researchers argued that to properly align the project objectives, an owner has to consider business planning, design, construction, operation and maintenance, early in the project lifecycle. 


\section{Project Delivery and Community Energy Infrastructure}

Power generation and alternative energy projects are complicated, highly regulated and often fast-tracked projects that come with substantial financial risks (Gonzales, 2009). New district energy projects are no exception. Russell and Tawiah (2006) found that the willingness to share both the risks and rewards of adopting innovative solutions for project procurement strategies could be a powerful driver for innovation. This willingness was linked to the risk attitudes of project stakeholders and their understanding of the riskinnovation relationship. Risks differ significantly from project to project and risk allocation is a key part of any successful procurement and management strategy (Miller et al., 2000). A comprehensive lifecycle analysis of a district energy project is the key factor to making an informed procurement decision (Damecour, 2008). It would follow that the owner's selection of an appropriate PDCS is essential to ensure the success of a district energy project over its entire lifecycle.

\section{PDCS Selection Factors}

Identifying the project characteristics and objectives should be the first step in the owner's PDCS decision-making process. Gordon (1994) is one of the earliest researchers who defined the "project drivers" that he suggested should influence the project delivery decision. Gordon (1994) identified time constraints, flexibility for change, pre-construction service needs, design process interaction, and financial constraints as key project drivers. In order to maximize the benefits offered to them, owners will need to adequately define drivers, while understanding the characteristics of each delivery method and the conditions of the construction market (Gordon, 1994). 
Based on the comprehensive literature review, a list of 22 selection factors that are applicable for district energy projects were formulated. Section for PDCS Selection Factors explains the selected factors in detail. Owners and operators of actual district energy projects in Canada were asked to evaluate and prioritize the identified PDCS selection factors (Section for PDCS Selection Factors and Table 2). They were further asked to add any new factors, if applicable. No additional PDCS selection factors were identified by the research participants.

\section{PDCS Effectiveness}

A key step in the development of a PDCS decision support framework is to form an understanding of the relationship between the owner's PDCS selection factors and the available PDCS alternatives. There are two ways that this has been studied. One is by collecting performance-based empirical data to validate a cause and effect relationship between PDCS alternatives and project outcomes. The other is through the aggregated opinions of experts with a wide range of experience in project delivery.

\section{Performance-Based Empirical Studies}

PDCS effectiveness can be determined through a performance-based empirical investigation of the project delivery systems, using data collected from completed projects to draw conclusions about PDCS effectiveness. One of the most often cited papers to use this approach is Konchar and Sanvido (1998)'s Comparison of U.S. Project Delivery Systems. The authors compared the cost, schedule, and quality performance of US building projects 
that had used design-bid-build, construction management, and design-build delivery methods.

While collecting larger and more varied samples from completed projects has proven to be a valid methodology to measure project performance against the PDCS alternatives, there were several reasons why it was not used for the research that supports this paper.

1. Konchar and Sanvido (1998) focused on a wide range of capital projects that allowed for a broad scope of data collection possibilities. The research presented in this paper is limited to district energy projects and relatively few of these projects have been built. Therefore, empirical data on project performance is very limited.

2. Much of the data required to validate the project's performance through empirical performance-based testing are protected as a result of business confidentiality. Access to data and the ability to validate the accuracy of data would be difficult for district energy projects in Canada.

3. Konchar and Sanvido (1998)'s research was limited to three PDCS selection factors to measure the effectiveness of three PDCS alternatives. This research looks at 22 selection factors and 10 PDCS alternatives, making data collection that relies on performance based metrics, a massive undertaking.

4. Of the three measurements of performance selected by Konchar and Sanvido (1998) only cost and schedule was measured objectively. Measurement of quality required subjective ranking by the research participants and was based on perception. Many of the lifecycle objectives identified in the 22 selection factors used for this study also cannot be measured objectively and therefore are better suited to the methodology adopted in this research. 


\section{The Delphi Method}

The Delphi method is a highly used and recognized method for collecting data from participants within their area of expertise. The technique is known as a group communication procedure, which target to attain a convergence of judgment on certain real-world problems. The Delphi method is well suitable as a technique for opinion-building with a sequence of questionnaires provided multiple repetitions to gather data from a group of select individuals. The Delphi approach has gained popularity for research problems where the phenomenon being studied is complex or where performance-based empirical data are not available. With the Delphi method, the experiences, knowledge, and presumptions of experts are collected through an interactive process, normally by interview or survey. Delphi is able to reveal and utilize the tacit knowledge of experts and allows others to view and evaluate it (Lilja et al. 2011). In contrast, this performance-based data collection methodology relies on explicit knowledge, drawing conclusions from events that have occurred, where documentation is reliable and available.

When planning an infrastructure project, future situations are unique and most probably not repeatable events. Therefore, any future predictions are based on probability. The Delphi method relies on the assumption that experts are able to place their greater experience behind their predictions, which then carry more weight than those of people with no direct experience (Lilja et al., 2011). In this way, experts are in the best position to assess potential project risks and assign the appropriate contract strategy alternatives to mitigate those risks.

It is understood that in studies where the aim is to collect qualitative data and information from a limited group of experts, or a group of people that can be regarded as 
experts, because of their knowledge and/or experience, some variation of the Delphi method is an appropriate research methodology for the researchers to consider (Lilja et al., 2011).

\section{RESEARCH METHODOLOGY}

To determine the stakeholder's contribution developing a policy or implementing a project, structured tool as Delphi method can be used (Varvasovszky and Brugha, 2000) Consistent with the Delphi approach, multiple tools were used to conduct this research, including: questionnaires, interviews, workshops, and a comprehensive literature review. Data were compiled, analyzed using a variety of methods and ultimately resulted in the decision support tool described briefly in this paper. Figure 1 shows a summary of the research methodology used to support this research. With this methodology, there is no cause-effect or causal relationship to satisfy. Then the internal validity is not a concern. $<$ Insert Figure 1 >

\section{Case Study Projects}

As mentioned above, seven unique case studies were conducted for this research. These were all district energy projects that have been built (or are currently under construction) within the past 15 years, in Canada.

General information was gathered about these projects, including technical data about the system operation. Additionally, specific information about the PDCS decision process and the relevant selection factors was collected. Data was gathered primarily through phone interviews with owner representatives. Participants were asked questions from a preprepared questionnaire. By combining random sampling and expert sampling methods, 
external validity has been addressed of the research. The data on case study projects were retrieved from interview transcripts, unless otherwise noted. In order to verify the interview data and to enhance general understanding about the case study projects, relevant web sites were reviewed for each project. These sources are not referenced in order to protect the confidentiality of the projects and that of the research participants. Table 01 indicates the participants' demographic information.

$<$ Insert Table $1>$

In addition to providing technical information, each of the case study participants was asked to identify the PDCS alternative they utilized to deliver their project. The PDCS methods varied widely from project to project. Table 2 shows a summary of the PDCS alternatives that were used for each of the case study projects and provided the data (PDCS used) for the project available to study. It just shows the diversity of experience of the participant selected for the case study.

$<$ Insert Table $2>$

Design-Bid-Build (DBB): The owner contracts separately for the design and construction of the facility.

Design-Bid-Build with Early Procurement (DBB-EP): Similar to DBB, except that the owner separately procures some large pieces of equipment and/or materials early in the project. Design-Bid-Build with Project Manager (DBB-PM): This method is used when the required expertise of project management is not available with the owner company.

Construction Manager (CM): The owner contracts with a construction manager who is engaged early in the design phase and acts as the owner's agent. 
Construction Manager at Risk (CMR): Similar to CM except that the CM and the owner agree to a guaranteed maximum (fixed) price for the construction work, based on the detailed design documents.

Design-Build (DB): The owner prepares a performance specification for the project and then contracts with a single entity for the detailed design and construction of the facility. Multiple Design-Build (MDB): Similar to DB, however this delivery system may work on a mega-project, where the scale of the construction makes it reasonable to partition the project into multiple design build components.

Multiple Prime Contractors (MPC): Multiple prime contractors work with the same designer was used for all scopes of work.

Design-Build-Operate-Maintain (DBOM): Similar to DB, except that the operation and maintenance of the facility is included in the contract, for a fixed period of time.

Public Private Partnership (P3): Similar to DBOM, except that the owner contracts with a single private entity and financing of the project is included, for a fixed period of time.

\section{PDCS Selection Factors}

Bowers et al. (2003), identified and validated thirty potential PDCS selection factors that apply to a wide range of capital facility projects. Oyentuji (2001) further refined Bowers' list to twenty selection factors. Using Oyentuji (2001), as the starting point, the authors redeveloped a list of 22 PDCS selection factors in the context of district energy projects. Case study participants were asked to score the importance of each selection factor, from the following list:

1. Minimal capital cost was critical to project success 
2. Construction completion within original capital budget was critical to project success

3. Minimal operating and maintenance cost was critical to the project success

4. Owner wished to defer capital cost over the life of the project

5. Owner required early and reliable capital cost figures to facilitate financial planning and business objectives

6. Owner required early and reliable operating and maintenance cost figures to facilitate financial planning and business objectives

7. Owner required early and reliable energy output and system efficiency figures to facilitate financial planning and business objectives

8. Owner required certainty of fuel cost to facilitate financial planning and business objectives

9. Owner wished to assume minimal financial risk on the project

10. Completion within original schedule was critical to project success

11. Early procurement of long lead items was critical to project success

12. An above average number of changes were anticipated on this project

13. Confidentiality of business and/or engineering details was critical to project success

14. The owner desired a high degree of control and influence over the project design and construction

15. Owner desired a high degree of control and influence over the design of operation and maintenance of the facility

16. Owner desired substantial use of their own resources in the commissioning, operation and maintenance of the facility 
17. Owner desired minimal use of their own resources in the commissioning, operation and maintenance of the facility

18. Owner desired substantial influence and control over the pre-planning phase of the facility

19. Owner desired minimal influence and control over the pre-planning phase of the facility

20. Project scope of work was not well defined at the start of the construction contract

21. Owner wished to limit number of parties directly accountable for the project's performance

22. Owner required certainty of emissions and other environmental concerns to accomplish their pre-planning objectives

The PDCS score was a subjective measure and a baseline was needed to enable the scoring. Each participant was told that their most important selection factor (or factors) would receive a score of 100 and that the relative importance of all other factors should be judged against that score. The value of 0 and 100 in the scale represented "not significant" and "absolutely significant" respectively. In addition, if a factor is not applicable, the factor was rated as "N/A" in the questionnaire. The questionnaire was completed in an interview format, so the participants could be asked periodically to revisit their high scores to ensure that the relative importance of the scoring was maintained. This process also helped the participant to clarify any doubts related to the questionnaire and rating scale.

A transcript of the discussion was sent to the participants within a day of the interview. They were asked to check it for accuracy and to provide any comments, if necessary. Two participants asked to fill out the questionnaire on their own and submit it without the interview process. In one case, the completed questionnaire was taken at face 
value without the opportunity to revisit the data. In the other cases, there was an opportunity to review the answers with the participant and some minor changes were made to the final transcript.

The use of a 1-100 scale allowed the participants to visualize the scoring as a percentage. This assisted them in establishing the relative importance of each selection factor against their own top score. It also provided the most flexibility for future analysis of the data as these scores could be easily converted to $1-10$ or $0-1$ score, if needed. Participants were told that they could have several selection factors that rated 100; however they had to be of equal importance. The selection factor scores for the seven valid case study projects are shown in Table 3.

$<$ Insert Table $3>$

\section{Finalizing of PDCS Selection Factor Scores}

The following section describes the changes made to the final list of selection factors, based on the analysis of scoring received from the case study participants, shown in Table 2.

Selection factor \#13 referred to confidentiality of "business objectives and/or engineering details". The case studies showed that, with district energy projects, the owner does not have the proprietary technology and is not seriously concerned about protecting it. The owner's business objectives are however very important and in many cases had to be closely guarded. Selection factor \#13 was changed to include only the confidentiality of business objectives.

Selection factor \#15 referred to the owner's level of influence over the design of the operation and maintenance of the facility. It became apparent during the interviews that this 
question was redundant, as it was already covered in selection factor \#14, which refers to the owner's desired level of control over design and construction. A comprehensive design of the facility will inherently incorporate the operation and maintenance requirements.

Selection factor \#15 was deleted from the final list for the Relative Effectiveness Value (REV) workshops and was not used in the decision support tool developed for this research.

Selection factor \#17 referred to the owner's desire to have minimal use of their own resources in the commissioning, operating, and maintenance of the district energy facility. Participants felt that selection factor \#17 was a redundant question, particularly since selection factor \#16, the owner's desire to have maximum use of their own resources, is the opposite to it. It therefore scored very low, or was left unanswered. However, it is important for the PDCS selection tool that the owners are given a choice of high or low involvement of their own forces in the operation and maintenance of the facility. These two objectives drive different PDCS alternatives. Again, the fact that this selection factor scored low could also be a result of the low number of case study projects. Selection factor \#17 was left in the list for the REV workshops, even though it scored low.

Selection factor \#19 referred to the owner's desire to have minimal influence and control over the pre-planning phase of the facility. This selection factor scored very low. It was evident from the case study interviews that this was not an objective that an owner would consider. If they did not have the capacity to conduct the pre-planning with their own forces they would hire a consultant to act as an agent on their behalf. Selection factor \#19 was deleted from the final list for the REV workshops and was not used in the decision support tool. 
Selection factor \#20 referred to the project scope of work being poorly defined at the start of the construction contract. This selection factor also scored very low. Two problems with this selection factor were revealed during the interviews. First, it did not read as an objective. While the other factors used words like "required", "desired" and "wished", selection factor \#20 described a potential condition of the project. In this way it cannot be considered as an objective. Second, it is highly unlikely that an owner would have this as an objective. It is more likely that a desire to fast track the schedule would cause an owner to defer key decisions for business reasons and to make changes as the project progressed. In this way selection factor \#12, which refers to the owner anticipating a high level of changes on the project, is a more appropriate measure of this objective. Selection factor \#20 was deleted from the final list for the REV workshops and was not used in the decision support tool.

Selection factor \#21 referred to the owners desire to limit the number of parties directly accountable for project performance. The average and median score for selection factor \#21, was 32 (with a median score of 30). This is a relatively low score and could signal that this was not an important selection factor to owners of these projects. However, because of the relatively low number of case study projects, the average and median scores were less significant indicators than they would be with a larger data sample. Selection factor \#21 was scored highly by case study \#3 and it was felt that this one high score was enough to include it in the selection criteria for PDCS alternatives.

The concept of sustainability and green construction is currently very popular in North America. Construction owners prefer to market and brand their projects based on its' environmental footprints. Therefore, they prefer to include information related to 
environmental and emissions control in the early decision making process. Factor \#22 was added to understand owners' priority in environmental related concerns, early in the decision making process.

A final list was established and measurement attribute was developed for each of the validated selection factors. The final list of validated selection factors and their corresponding measurement attributes is shown in Table 4.

$<$ Insert Table $4>$

The measurement attribute was used to establish the effectiveness of the PDCS in achieving that selection factor. For the measurement attribute, the wording of the selection factor was changed to the present tense, to accommodate future projects as opposed to projects that had already occurred. For example where selection factor 1 reads, "Minimal capital cost is critical to project success", its measurement attribute reads, "The delivery system is effective in ensuring the lowest reasonable capital cost for design and construction." The selection factor measurement attributes became the basis for validation of the REV scores.

\section{PDCS Relative Effectiveness Values}

Data collection for the REV scoring was conducted over three workshop sessions with randomly selected senior construction professionals, from varied backgrounds and experienced in a wide range of project delivery alternatives. 


\section{Development of the REV Worksheet}

The first step in establishing REV scores was to develop the REV worksheet used for scoring. In order to accomplish this, the list of PDCS alternatives that would be considered in the PDCS selection tool had to be finalized. The original pilot test group had been asked to review the global set of PDCS options that were listed in the draft questionnaire. This set was based on the list established by Bowers et al. (2003), with additional PDCS alternatives deemed by the researcher to be appropriate for district energy projects. Through discussion during the case study interviews and subsequent discussion with experts in the field, it was apparent that some changes to the original list of PDCS alternatives list were necessary for the REV workshops.

. The revised list of PDCS alternatives that was used for the final REV worksheet is as follows:

1. Design-Bid-Build (DBB)

2. Design-Bid-Build with Early Procurement (DBB-EP)

3. Multiple Design-Bid-Build (M-DBB)

4. Construction Management (CM)

5. Construction Manager at Risk (CMR)

6. Design-Build (DB)

7. Design-Build-Operate-Maintain (DBOM)

8. Public Private Partnership (P3) 


\section{PDCS Effectiveness Value Workshops}

In selecting participants for the REV workshops it was important to find individuals who were not involved in the case study interviews at which the selection factors were determined. The case study projects exhausted the group of project managers with district energy experience who were available for this research. As the objective of the REV workshops was to align selection factors with PDCS alternatives, finding individuals with extensive experience in the delivery of major public industrial, commercial, and institutional (ICI) building projects was very important. The selection factors validated from the case studies are broad objectives and could apply to a variety of infrastructure projects, not just to district energy projects. It was felt that, while it was necessary that the workshop participants understood the broad objectives of the study, they did not need to have direct experience with district energy projects to accurately score the PDCS effectiveness.

As discussed previously, the selection of the PDCS is the owner's decision. In planning the methodology for validating the REVs, it was obvious that the inputs of project managers working for large public-sector owners were essential to establishing accurate REV scores. However, in many instances the principal design team and/or construction manager may also have significant influence over the owner's PDCS decision. Often an owner with limited project management expertise, or limited experience with a specific type of project, will rely on third party construction professionals to contribute to the PDCS decision. For this reason, workshops \#2 and \#3 were held with project managers representing contractors and design professionals respectively.

The workshops were conducted with Delphi approach. It was a discussion with the participants to further understand reasoning for PDCS individual rankings in the 
questionnaire. As a group, the participants were encouraged to find common grounds for PDCS selection factors and its' importance. The REV workshops were each held in the offices of the participant organizations. Participants were briefly introduced to the research project and the overall goal of the research was discussed. The process used to validate the 19 selection factors on the REV worksheet was explained to the workshop participants.

The eight PDCS alternatives in the REV worksheet were also reviewed to ensure the terminology was clearly understood by all parties. In all three workshops, the eight delivery methods were familiar to all of the participants prior to the meeting. The workshops ranged from one and a half to two hours.

REV workshop \#1 was attended by a group of three senior project managers from the construction department of a large public institution in Vancouver, BC. These individuals are responsible for the delivery of large institutional, industrial, and commercial building projects. REV workshop \#2 was attended by a group of three senior project managers from a mid-sized general contracting and construction management firm with offices in Victoria and Vancouver, BC. These individuals are responsible for the construction of large ICI building projects for clients across Western Canada. REV workshop \#3 was attended by a group of two principal architects, an associate architect, and two senior project architects from a midsize architectural firm in Vancouver, BC. These individuals were responsible for the design of large ICI building projects throughout Western Canada. 


\section{Analysis of Relative Effectiveness Value Workshops}

An overview of the data reveals a fairly good alignment between the REV scores gathered from the three separate workshops, with the following exceptions; hence, it can be concluded that Internal Consistency Reliability and Inter-Rater or Inter-Observer Reliability (in terms of reliability) were achieved.

There was a relatively large discrepancy in the scores received from workshop \#1 for selection factors 5, 7 and 8. The need to help accurately set a baseline and range for scoring was not well understood at this early session. For this reason, there was a perception from the participants that the scores were to be either very high or very low. There was little consideration for the mid-range. For example, where DBB may not allow for the most certainty around the capital cost until the bids are received, a well-managed design process with a qualified cost consultant on-board will bring some level of cost certainty during preplanning.

With this lesson in mind (and consistent with the Delphi approach), key representatives from workshop \#1 were re-interviewed. There was further discussion about the range of scoring available. The assumption of a base level of competency from the consulting professionals, for all delivery options, was also discussed. Scoring from the other two workshops was shared with this individual during this second interview. The original scores were revised and the new scores were more consistent with those from the other workshops.

Selection factor 17 also relates to the owner's role in pre-planning and was subject to the same misunderstanding for the members of workshop \#1. There was an assumption in workshop \#1 that a well-written DB performance specification would provide control over 
pre-planning. It was revealed in the subsequent workshops that when control over the design phase was handed over to the DB contractor the influence of the owner was limited compared to the DBB and CM options. Through further discussion with the representative from workshop \#1, the scores for selection factor 17 were also revised.

Another discrepancy was found in the scoring for selection factor 10. While the other two groups felt that a CM delivery method allowed the owner to be much more contractually agile and therefore able to expedite the schedule where necessary, the participants of workshop \#3 did not see it this way and scored it low.

In further discussions with a key representative from workshop \#3 it was agreed that with the integrated design options, control over time and schedule lies with the DB, DBOM or P3 contractor, not with the owner. Consequently, the owner has little influence over the schedule, other than to enforce the contractual completion date. It was agreed that CM and CMR would allow the most flexibility and therefore the most control for the owner. Consequently, the scores from workshop \#3 for selection factor 10 were revised to be closer with the scores from the other two workshops.

The other discrepancy was noted for selection factor 12. Most PDCS alternatives scored fairly closely in all workshops. Discussion with the representatives of workshop \#1 confirmed that they had not correctly understood the factor \# 12 and their scores reflected this. Therefore, the relevant scores in workshop\#1 were removed from the aggregate scoring sheet.

Table 5 shows a summary of the results from the three REV workshops. A simple average has been used to aggregate the three scores into one for each PDCS alternative. This 
single score was used to support the background calculation in the PDSC decision support tool.

$<$ Insert Table $5>$

Table 5 shows a distinct relationship between the 19 validated PDCS selection factors and the ability of each PDCS alternative to meet those objectives. Table 5 may suggest the use of PDCS alternatives that may have otherwise not been considered. Having determined PDCS selection factors and their REVs for potential PDCS, all the parameters are determined to calculate the final rankings; then, it is possible to go for the PDCS Selection Support Tool.

\section{PDCS SELECTION SUPPORT TOOL DEVELOPMENT}

The PDCS decision support tool developed in this research will not provide a single conclusive answer to the PDCS question for a district energy project. However, it will assist the decision maker to take a step-by-step approach to the selection. The tool will encourage them to think about the key lifecycle objectives. This process will enhance the strength of their eventual PDCS delivery decision. Figures 2 and 3 illustrate screen shots of this tool. Only important (key) screen shots have been included in the paper.

- Step 1: General project information

The information gathered in step one includes: general project information (used to populate reports generated by the program), summary technical information (used to populate step two), and project cost information (used to frame the PDCS decision alternatives and to determine whether P3 is a valid PDCS alternative). This general information about cost, schedule, and lifespan of the facility will create some context around the overall project objectives for the decision maker. 
- Step 2: PDCS Selection Bundle

Step 2 requires the user to "bundle" the components of their district energy project, such that different PDCS can be applied to these different bundles. The ability to bundle the project components allows the user to choose and rank different selection factors for each bundle. This will drive different PDCS selection metrics from the decision support tool. Step 2 also provides the user with a general definition of each PDCS alternative through a link to diagrams that describe the phasing and the relationships for each PDCS alternative.

- Step 3: Rank the PDCS Selection Factors Under the Step 3, the PDCS selection factors are chosen and ranked. The tool requests the user to place top ten selection factors in the order of importance for each PDCS selection bundle. The components contained in each bundle are listed on the user screen. The pilot decision support tool is currently designed such that the \#1 ranked selection factor is valued at $100 \%$ and the value of each subsequent rank is reduced by $10 \%$ (i.e. Rank $\# 9$ is multiplied by $90 \%$ and then multiplied against the aggregated REV for each PDCS). As an example, the screen shot to rank bundle no. 1 has been shown in Figure 2.

$<$ Insert Figure $2>$

- Step 4: PDCS Selection Alternatives

The final screen provides the user with a summary showing all of the PDCS alternatives and how each ranks based on the weighted selection factors which was entered in Step 3. Each bundle is shown separately, with the understanding that a 
different PDCS decision could be made for each. Results are shown both in tables and in a bar chart format.

$<$ Insert Figure $3>$

\section{Validation and Fine-Tuning of the PDCS Selection Support Tool}

The developed PDCS decision support tool was validated with participants who had not previously been involved in the study. Randomly selected experienced project managers were necessary to comment on the results of the decision support tool. Finding such project managers who had experiences in district energy projects were a significant challenge. With rigorous efforts and consultations, the researchers were able to locate three senior project managers who had over 30 years' of experience in district energy projects. The steps to validate the pilot version of the decision support tool were as follows:

1. Initial meetings were held to introduce the overall research project, the methodology behind the decision support tool, and the steps required to use the tool.

2. The research participants were given two weeks to review the program on their own.

3. A second brief meeting was held after one week, at the request of the participant, to answer general questions about the overall mechanics of using the tool.

4. A final meeting was held after two weeks to debrief.

5. Participant opinions on the tool were discussed in detail, with specific project examples, and the tool was fine-tuned with the recommended changes.

All the participants were well aligned with the final results provided by the decision support tool. Not a single comment was given to challenge the final PDCS selection factors proposed by the tool. They all appreciated the usefulness of the tool for future decision making in 
district energy projects. However, three main deficiencies were identified in the pilot test (steps 1-4). They are:

1. Better description and instructions for choosing a PDSC selection bundle.

2. Better instructions on how to rank the PDCS selection factors.

3. Better visualization capability through an improved display of the results on the summary page.

Based on the feedback, the instructions for Step 2 were revised to add more description to the term "PDCS selection bundle". The user is now told to bundle the components that they feel are likely to have the same selection factors. They are also reminded that a second (or third) selection bundle should be selected only if the lifecycle objectives of that component are expected to be significantly different from the other components. Future development of the tool could include additional programming that helps the user better organize and visualize the component into bundles.

The pilot test also identified that if one or more inputs used to rank the selection factor in Step 3 were left empty, the summary sheet would not provide a PDCS recommendation for that bundle. This function was intentional to ensure consistency in scores from bundle to bundle. As well, it seemed unclear to the pilot test participants that the same selection factor could be selected as many times as needed. The ability to enter the same selection factor in multiple cells within each bundle (and consequently improve the importance ranking of that factor) could also need to be clearer in future development of the tool. 


\section{Conclusions}

The research conducted to support this paper was able to fill a gap in the current body of knowledge by introducing the idea of long-term objectives as drivers of project delivery and contracting decisions. By limiting the study to district energy projects, the study was able to leverage the unique objectives of those projects, specifically to demonstrate the relationship between PDCS selection factors and PDCS effectiveness. The developed methodology will also help to shape PDCS decisions for projects with similar profiles, throughout the industry, and thus ensure future success of such projects.

This research project identified unique long-term objectives of district energy projects, which focused on the entire project lifecycle. These factors include:

- Certainty of operating and maintenance costs over all phases of the project lifecycle and responsibility for resources to be assigned to operation and maintenance.

- Certainty of long-term fuel cost throughout the operation and maintenance phase, especially where alternative energy sources are being considered.

- Flexibility to change scope and certainty of development needs where system must be built to accommodate unconfirmed energy demand scenarios.

- Certainty of emissions and other environmental concerns, especially where alternative energy sources.

- This research helps to enhance understanding of the relationship between PDCS alternatives and the key PDCS selection factors, over the life of district energy projects.

- This research helps the owners of Canadian district energy projects to select the best PDCS alternative (or alternatives) to meet the project's key long-term objectives. 
- PDCS decision support tool developed in this research provides additional information to project owners towards PDCS that they may have not otherwise considered.

These PDCS alternatives often included integrated delivery solutions and partnering opportunities such as DBOM and P3.

The decision support tool presented in this paper can be applied to any district energy project with some fine-tuning. In addition, the proposed methodology to assess the PDCS is applicable to any region or a country. This research project focused on data sources in Canada due to data accessibility limitations. However, the base knowledge presented in this paper is universal. 


\section{References}

Akhtari, S., Sowlati, T., and Day, K. 2014. Optimal flow of regional forest biomass to a district heating system. International Journal of Energy Research, 38(7), 954-964.

Anderson, S. D., Damnjanovic, I., 2008 . Selection and evaluation of alternative contracting methods to accelerate project completion. National Research Council (U.S.). Transportation Research Board, National Cooperative Highway Research Program, American Association of State Highway and Transportation Officials, and U.S. Federal Highway AdministrationWashington, D.C

Bowers, D., Bhargava, R., and Anderson S. 2003. Characteristics of integrated project delivery and contract strategies No. 165-11 a Report to CII, Construction Industry Institute. Austin Tx.

Cheung, S.O., Lam, T., and Leung, M. 2001. An analytical hierarchy process based procurement selection method. Construction Management and Economics, 19(4), 427-437.

Damecour, R. 2008. Purchasing district energy services - A case for lifecycle analysis. Summit - Canada's Magazine on Public Sector Purchasing, Ottawa,14-15.

Ministry of Energy, Mines and Petroleum Resources of British Coulmbia. 2010. District Energy Sector in British Columbia. Available from www.empr.gov.bc.ca/EAED/.../DistrictHeating27May2010.pdf

Gilmour, B., and Warren, J.. 2008. The new district energy: Building blocks for sustainable community development, Canadian District Energy Association Toronto,ON. 
Gonzales, A. J. 2009. Mitigating cost and schedule risks on power generation construction projects. 53rd AACE International Annual Meeting 2009, June 28, 2009 - July 1, Seattle, Washington, USA.

Gordon, C. M. 1994. Choosing appropriate construction contracting method. Journal of Construction Engineering and Management, 120(1), 196-210.

International District Energy Association. 2005. IDEA report: The district energy industry From: http://www.districtenergy.org/assets/pdfs/IDEAIndustryWhitePaper.pdf

International District Energy Association. 2009. Quick History of District Heating. Available from http://www.districtenergy.org/in-our-second-century-of-service.

International District Energy Association. 2011. About district energy, Available from http://www.districtenergy.org/

Konchar, M., and Sanvido, V. 1998. Comparison of U.S. projects delivery systems. Journal of Construction Engineering and Management, 124(6), 435-444.

Lilja, K. K., Laakso, K., and Palomki, J. 2011. Using the delphi method. Technology Management in the Energy Smart World (PICMET), 2011 Proceedings of PICMET '11, 1-10, Portland, Oregon, USA

Miller, J. B., Garvin, M. J., Ibbs, C. W., and Mahoney, S. E. 2000. Toward a new paradigm: Simultaneous use of multiple project delivery methods. Journal of Management in Engineering, 16(3), 58-67.

Oyentuji, A. A. 2001. Methodology for selecting project delivery and contract strategies for capital projects, Ph.D. thesis, Texas A and M University.

. Pishdad P.B., and Believau, Y.J. 2010. Analysis of existing project delivery and contracting strategy (PDCS) selection tools with a look towards emerging technology. Emerging 
Technology, 46th Annual Associated Schools of Construction International Conference, Wentworth Institute of Technology, Boston, Massachusetts,USA.

Rezaie, B., and Rosen, M.A. 2010. District heating and cooling: Review of technology and potential enhancements. Applied Energy, 93(2012), 2-10.

Russell, A. D., Tawiah, P., and De Zoysa, S. 2006. Project innovation - A function of procurement mode. Canadian Journal of Civil Engineering, 33(12), 1519-1537.

Statistics Canada 2012, Canada's population clock, Ottawa,ON,Canada,From: http://www.statcan.gc.ca/ig-gi/pop-ca-eng.htm,

Touran, A., Gransberg, D. D., Molenaar, K. R., Ghavamifar, K., Mason, D. J., and Fithian, L. A. 2009. "TCRP Report 131: A Guidebook for the Evaluation of Project Delivery Methods". Transportation Research Board, 2009, Washington, D.C. (USA)

Trauner Consulting Services. 2007. Innovative procurement practices - alternative procurement and contracting methods No. 53A0104) California Department of Transportation,CA, USA.

US Department of Energy. 2011. Federal energy management program - distributed energy resource basics, Washington, DC,USA. From:http://www1.eere.energy.gov/femp/technologies/derchp_derbasics.html

Varvasovszky, Z. and Brugha, R. 2000. A stakeholder analysis. Health Policy Plan. 2000. 15(3): 338-345. doi: 10.1093/heapol/15.3.338

Windsor Utilities Commission. 2014. Why district energy,Windsor, ON,Canada. Available from http://www.wuc.on.ca/dew/why district energy.cfm. 
Table 1: The participants' demographic information

\begin{tabular}{|c|l|c|}
\hline $\begin{array}{c}\text { CASE } \\
\text { STUDY NO. }\end{array}$ & JOB TITLE OF THE PARTICIPANT & $\begin{array}{c}\text { YEARS OF } \\
\text { EXPERIENCE }\end{array}$ \\
\hline 1 & Senior Director & 40 \\
\hline 2 & Senior Director & 35 \\
\hline 3 & Senior Manager & 30 \\
\hline 4 & Senior Project Manager & 20 \\
\hline 5 & Senior Advisor & 20 \\
\hline 6 & Director of Engineering & NA \\
\hline 7 & Director of Land Development & \\
\hline & & \\
\hline
\end{tabular}


Table 2: PDCS Alternatives Used on Case Study Projects

\begin{tabular}{|c|c|c|c|c|c|c|}
\hline $\begin{array}{l}\text { Case } \\
\text { Study }\end{array}$ & DE Plant & Buildings & $\begin{array}{l}\text { DE Pipe } \\
\text { Materials }\end{array}$ & DE Pipe Civil Work & $\begin{array}{l}\text { Energy } \\
\text { Transfer } \\
\text { Stations }\end{array}$ & $\begin{array}{l}\text { Heat } \\
\text { Pumps }\end{array}$ \\
\hline 1 & \multicolumn{6}{|c|}{ M-DBB and DBB-EP (Phased) } \\
\hline 2 & DB (Turnkey) & \multicolumn{5}{|c|}{ CMR } \\
\hline 3 & \multicolumn{2}{|c|}{ DBB-EP } & & DBB & DBB & DBM \\
\hline 4 & \multicolumn{6}{|c|}{ RESEARCH PARTICIPANT DID NOT PROVIDE THE DETAILS } \\
\hline 5 & \multicolumn{6}{|c|}{ DBOM with Financing (Owner/Operator) } \\
\hline 6 & \multicolumn{6}{|c|}{ CMR } \\
\hline 7 & $\begin{array}{l}\mathrm{DBB} \\
(\mathrm{DBOM})\end{array}$ & DBB & $\mathrm{DBB}-\mathrm{MP}$ & (Phased) & & \\
\hline
\end{tabular}


Table 3: Summary of Selection Factor Scores from Case Studies

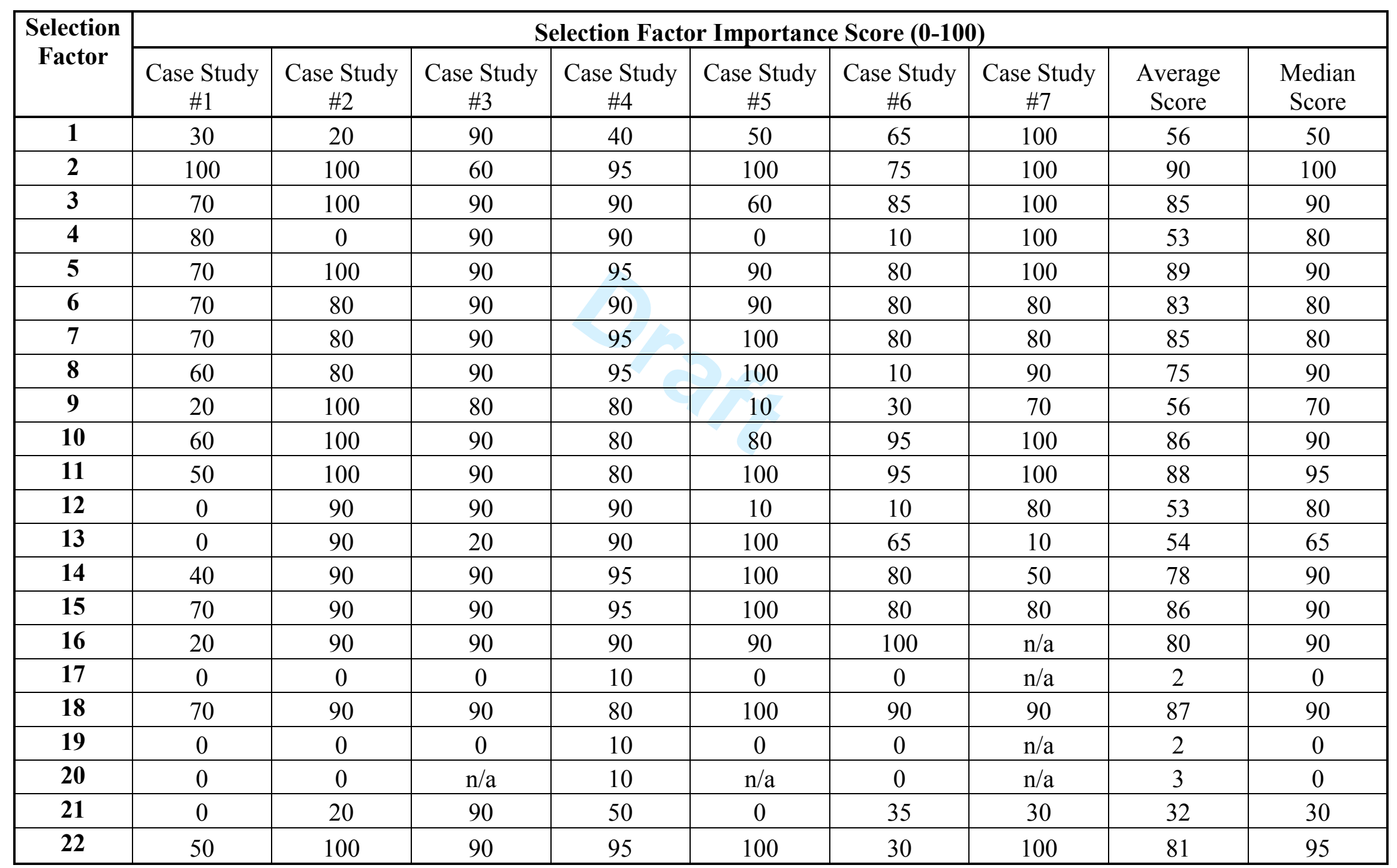


Table 4: Final Selection factors and Measurement Attributes

\begin{tabular}{|c|c|c|}
\hline & Selection Factor & Measurement Attribute \\
\hline 1 & $\begin{array}{l}\text { Minimal capital cost is critical to project } \\
\text { success }\end{array}$ & $\begin{array}{l}\text { The delivery system is effective in } \\
\text { ensuring the lowest reasonable capital cost } \\
\text { for design and construction }\end{array}$ \\
\hline 2 & $\begin{array}{l}\text { Construction completion within original } \\
\text { capital budget is critical to project } \\
\text { success }\end{array}$ & $\begin{array}{l}\text { The delivery system is effective in } \\
\text { controlling capital cost growth during } \\
\text { design and construction }\end{array}$ \\
\hline 3 & $\begin{array}{l}\text { Minimal operating and maintenance cost } \\
\text { is critical to the project success }\end{array}$ & $\begin{array}{l}\text { The delivery system is effective in } \\
\text { ensuring lowest reasonable operating and } \\
\text { maintenance cost over the life of the } \\
\text { project }\end{array}$ \\
\hline 4 & $\begin{array}{l}\text { Owner wishes to defer capital cost over } \\
\text { the life of the project }\end{array}$ & $\begin{array}{l}\text { The delivery system is effective in } \\
\text { deferring capital cost over the life of the } \\
\text { project }\end{array}$ \\
\hline 5 & $\begin{array}{l}\text { Owner requires early and reliable capital } \\
\text { cost figures to facilitate financial } \\
\text { planning and business objectives }\end{array}$ & $\begin{array}{l}\text { The delivery system is effective in } \\
\text { ensuring certainty around capital cost } \\
\text { estimates during the pre-planning phase }\end{array}$ \\
\hline 6 & $\begin{array}{l}\text { Owner requires early and reliable } \\
\text { operating and maintenance cost figures } \\
\text { to facilitate financial planning and } \\
\text { business objectives }\end{array}$ & $\begin{array}{l}\text { The delivery system is effective in } \\
\text { ensuring certainty around operating and } \\
\text { maintenance cost estimates during the pre- } \\
\text { planning phase }\end{array}$ \\
\hline 7 & $\begin{array}{l}\text { Owner requires early and reliable energy } \\
\text { output and system efficiency figures to } \\
\text { facilitate financial planning and business } \\
\text { objectives }\end{array}$ & $\begin{array}{l}\text { The delivery system is effective in } \\
\text { ensuring certainty around system } \\
\text { efficiency and energy production } \\
\text { estimates during the pre-planning phase }\end{array}$ \\
\hline 8 & $\begin{array}{l}\text { Owner requires certainty of fuel cost to } \\
\text { facilitate financial and business planning } \\
\text { objectives }\end{array}$ & $\begin{array}{l}\text { The delivery system is effective in } \\
\text { ensuring certainty around fuel cost } \\
\text { estimates during pre-planning phase }\end{array}$ \\
\hline 9 & $\begin{array}{l}\text { Owner wishes to assume minimal } \\
\text { financial risk on the project }\end{array}$ & $\begin{array}{l}\text { The delivery system is effective in } \\
\text { transferring a high level of financial risk } \\
\text { to third parties over the life of the project }\end{array}$ \\
\hline 10 & $\begin{array}{l}\text { Completion within original schedule is } \\
\text { critical to project success }\end{array}$ & $\begin{array}{l}\text { The delivery system is effective in } \\
\text { controlling against time extensions in the } \\
\text { design and construction phases }\end{array}$ \\
\hline 11 & $\begin{array}{l}\text { Early procurement of long lead items is } \\
\text { critical to project success }\end{array}$ & $\begin{array}{l}\text { The delivery system is effective in } \\
\text { promoting early procurement of long lead } \\
\text { materials, equipment and services for the } \\
\text { construction phase }\end{array}$ \\
\hline 12 & $\begin{array}{l}\text { An above average number of changes is } \\
\text { anticipated on this project }\end{array}$ & $\begin{array}{l}\text { The delivery system is effective in } \\
\text { incorporating changes during the } \\
\text { construction phase with minimal cost and } \\
\text { schedule impact }\end{array}$ \\
\hline
\end{tabular}




\begin{tabular}{|c|c|c|}
\hline 13 & $\begin{array}{l}\text { Confidentiality of business details is } \\
\text { critical to project success }\end{array}$ & $\begin{array}{l}\text { The delivery system is effective in } \\
\text { protecting confidentiality of the owner's } \\
\text { business objectives over the life of the } \\
\text { project }\end{array}$ \\
\hline 14 & $\begin{array}{l}\text { The owner desires a high degree of } \\
\text { control and influence over the project } \\
\text { design and construction }\end{array}$ & $\begin{array}{l}\text { The delivery system is effective in } \\
\text { ensuring the owner could control the } \\
\text { design and construction phases of the } \\
\text { project }\end{array}$ \\
\hline 15 & $\begin{array}{l}\text { Owner desires substantial use of their } \\
\text { own resources in the commissioning, } \\
\text { operating and maintaining the facility }\end{array}$ & $\begin{array}{l}\text { The delivery system is effective in } \\
\text { ensuring the owner would use their own } \\
\text { resources for commissioning, operation } \\
\text { and maintenance of the facility }\end{array}$ \\
\hline 16 & $\begin{array}{l}\text { Owner desires minimal use of their own } \\
\text { resources in the commissioning } \\
\text { operating and maintenance of the } \\
\text { facility }\end{array}$ & $\begin{array}{l}\text { The delivery system is effective in } \\
\text { ensuring the owner has minimal use their } \\
\text { own resources for commissioning, } \\
\text { operation and maintenance of the facility }\end{array}$ \\
\hline 17 & $\begin{array}{l}\text { desires substantial influence and } \\
\text { over the pre-planning phase of } \\
\text { lity }\end{array}$ & $\begin{array}{l}\text { The delivery system is effective in } \\
\text { maximizing the owner's role in the pre- } \\
\text { planning phase of the project }\end{array}$ \\
\hline 18 & $\begin{array}{l}\text { Owner wishes to limit number of parties } \\
\text { directly accountable for the projects } \\
\text { performance }\end{array}$ & $\begin{array}{l}\text { The delivery system is effective in } \\
\text { minimizing the number of contracts } \\
\text { directly with the owner over the life of the } \\
\text { project }\end{array}$ \\
\hline 19 & $\begin{array}{l}\text { Owner requires certainty of emissions } \\
\text { and other environmental concerns to } \\
\text { accomplish the pre-planning objectives }\end{array}$ & $\begin{array}{l}\text { The delivery system is effective in } \\
\text { providing certainly for the owner with } \\
\text { regards to emissions and environmental } \\
\text { issues over the life of the project. }\end{array}$ \\
\hline
\end{tabular}


Table 5: Summary of Final Average REV Scores

\begin{tabular}{|c|c|c|c|c|c|c|c|c|}
\hline \multirow{2}{*}{$\begin{array}{c}\text { Selection } \\
\text { Factor }\end{array}$} & \multicolumn{9}{|c|}{ Average PDCS Effectiveness Score } \\
\hline & DBB & DBB-EP & M-DBB & CM & CMR & DB & DBO-M & P3 \\
\hline $\mathbf{1}$ & 83 & 83 & 87 & 57 & 55 & 70 & 50 & 33 \\
\hline $\mathbf{2}$ & 67 & 70 & 80 & 68 & 73 & 73 & 73 & 63 \\
\hline $\mathbf{3}$ & 83 & 90 & 90 & 87 & 87 & 57 & 80 & 77 \\
\hline $\mathbf{4}$ & 0 & 0 & 0 & 0 & 0 & 0 & 7 & 100 \\
\hline $\mathbf{5}$ & 73 & 77 & 77 & 100 & 100 & 43 & 40 & 20 \\
\hline $\mathbf{6}$ & 53 & 53 & 53 & 52 & 55 & 40 & 100 & 100 \\
\hline $\mathbf{7}$ & 60 & 60 & 60 & 62 & 68 & 27 & 100 & 100 \\
\hline $\mathbf{8}$ & 53 & 53 & 53 & 58 & 60 & 27 & 100 & 100 \\
\hline $\mathbf{9}$ & 17 & 17 & 17 & 7 & 7 & 20 & 83 & 100 \\
\hline $\mathbf{1 0}$ & 23 & 70 & 70 & 100 & 90 & 53 & 30 & 25 \\
\hline $\mathbf{1 1}$ & 7 & 100 & 87 & 100 & 93 & 20 & 13 & 10 \\
\hline $\mathbf{1 2}$ & 40 & 43 & 27 & 77 & 35 & 10 & 7 & 3 \\
\hline $\mathbf{1 3}$ & 97 & 97 & 100 & 70 & 72 & 27 & 17 & 3 \\
\hline $\mathbf{1 4}$ & 87 & 87 & 97 & 92 & 85 & 13 & 10 & 10 \\
\hline $\mathbf{1 5}$ & 100 & 100 & 100 & 100 & 100 & 100 & 0 & 0 \\
\hline $\mathbf{1 6}$ & 0 & 0 & 0 & 0 & 0 & 0 & 100 & 100 \\
\hline $\mathbf{1 7}$ & 93 & 93 & 93 & 93 & 93 & 27 & 23 & 10 \\
\hline $\mathbf{1 8}$ & 60 & 57 & 53 & 0 & 60 & 70 & 87 & 100 \\
\hline $\mathbf{1 9}$ & 7 & 7 & 7 & 13 & 13 & 80 & 100 & 100 \\
\hline
\end{tabular}




\section{Figures}

Figure 1: Research Methodology

Figure 2: The screen shot to rank bundle no. 1

Figure 3: PDCS Selection Summary 


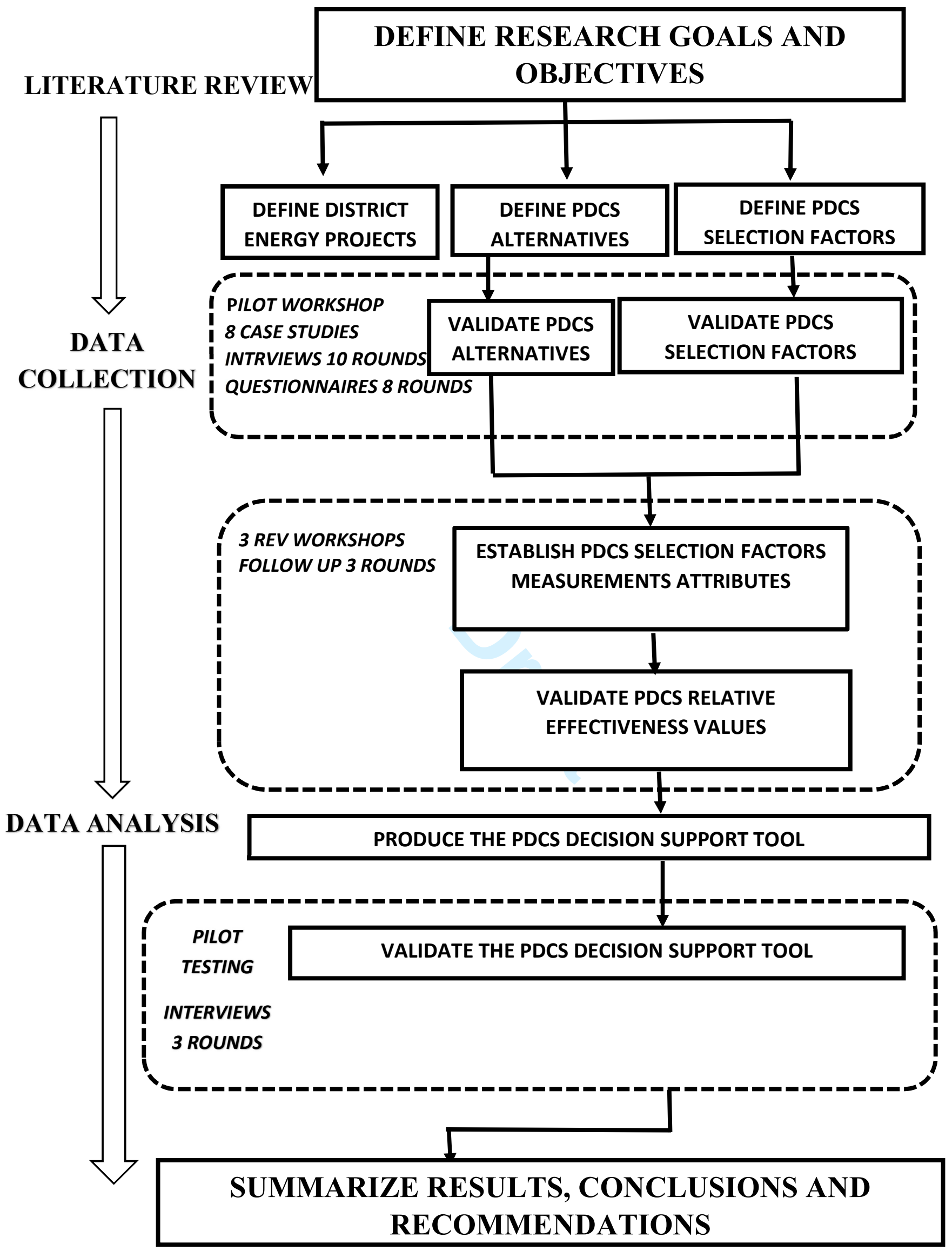

Figure 1: Research Methodology 
Step 3. Selection Factors:

Pick your ten most important selection factors from the list and rank them by placing the code in the selection bundle column

\begin{tabular}{|l|r|}
\hline Code & Selection Factors \\
\hline A & Minimalcaptal cost is critical to proje
\end{tabular}

\section{A $\begin{aligned} & \text { Minimal } \\ & \text { success }\end{aligned}$}

Construction completion within original capital budget is critical to project success

Minimal operating and maintenance cost is critical to the project success

D Owner wishes to defer capital cost over the life of the project

Owner requires early and reliable capital cost

E figures to facilitate financial planning and business objectives

Owner requires early and reliable operating

F and maintenance cost figures to facilitate financial planning and business objectives

Owner requires early and reliable energy

G output and system efficiency figures to

facilitate financial planning and business objectives

Owner requires certainty of fuel cost to

H facilitate financial and business planning objectives

Owner wishes to assume minimal financial risk on the project

J Completion within original schedule is critical to project success

Early procurement of long lead items is critical to project success

An above average number of changes is anticipated on this project

M Confidentiality of business details is critical to project success

The owner desires a high degree of control

N and influence over the project design and construction

Owner desires substantial use of their own

0 resources in the commissioning, operating and maintaining the facility

Owner desires minimal use of their own

$P$ resources in the commissioning operating and maintenance of the facility

Owner desires substantial influence and

Q control over the pre-planning phase of the facility

Owner wishes to limit number of parties

R directly accountable for the projects performance

Owner requires certainty of emissions and

S other environmental concerns to accomplish the pre-planning objectives

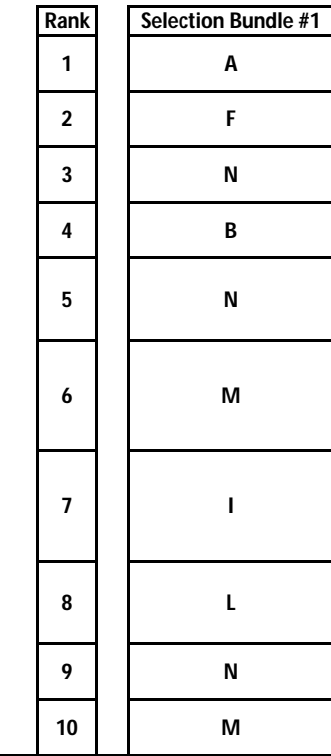

Bundle \#1 Components

\section{BACK \\ Selection Bundle \#2}

RESULT

Figure 2: The screen shot to rank bundle no. 1 
Location of district energy project:

\begin{tabular}{|c|l|}
\hline \multicolumn{2}{|c|}{ Selection Bundle \#1 } \\
\hline \hline Rank & \multicolumn{1}{|c|}{ Method } \\
\hline 6 & Design-Build-Operate-Maintain (DBOM) \\
\hline 4 & Construction Management (CM) \\
\hline 5 & Construction Management at Risk (CMR) \\
\hline 7 & Public Private Partnership (P3) or (DBOMF) \\
\hline 3 & Design-Bid-Build-Early Procurement (DBB-EP) \\
\hline 1 & Design-Bid Build (DBB) \\
\hline 1 & Multiple Design-Bid Build (M-DBB) \\
\hline
\end{tabular}

\begin{tabular}{|c|l|}
\hline \multicolumn{2}{|c|}{ Selection Bundle \#2 } \\
\hline \hline Rank & \multicolumn{1}{|c|}{ Method } \\
\hline 6 & Design-Build-Operate-Maintain (DBOM) \\
\hline 5 & Construction Management (CM) \\
\hline 7 & Construction Management at Risk (CMR) \\
\hline 1 & Public Private Partnership (P3) or (DBOMF) \\
\hline 4 & Design-Bid-Build-Early Procurement (DBB-EP) \\
\hline 2 & Design-Bid Build (DBB) \\
\hline 2 & Multiple Design-Bid Build (M-DBB) \\
\hline
\end{tabular}

\begin{tabular}{|c|l|}
\hline \multicolumn{2}{|c|}{ Selection Bundle \#3 } \\
\hline \hline Rank & \multicolumn{1}{|c|}{ Method } \\
\hline 4 & Design-Build-Operate-Maintain (DBOM) \\
\hline 7 & Construction Management (CM) \\
\hline 6 & Construction Management at Risk (CMR) \\
\hline 1 & Public Private Partnership (P3) or (DBOMF) \\
\hline 5 & Design-Bid-Build-Early Procurement (DBB-EP) \\
\hline 2 & Design-Bid Build (DBB) \\
\hline 2 & Multiple Design-Bid Build (M-DBB) \\
\hline
\end{tabular}
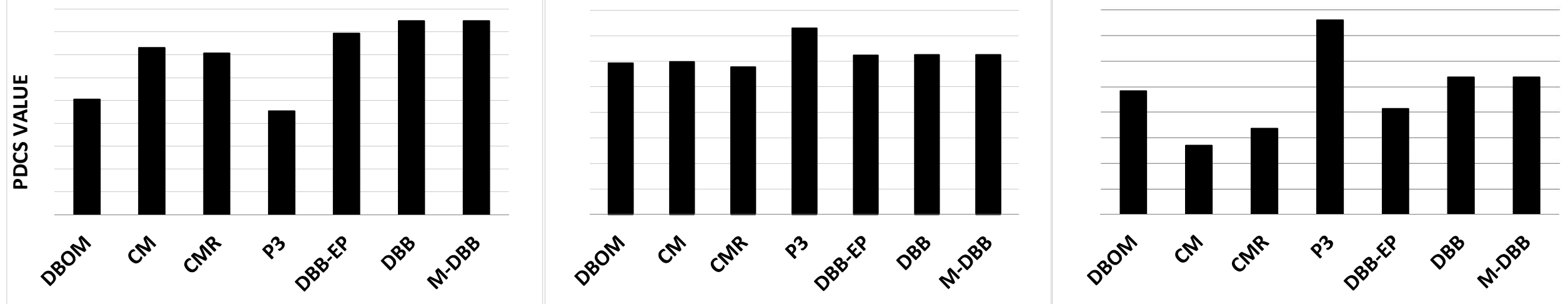

Figure 3:PDCS Selection Summary 